\title{
How Do We Monitor Oxygenation during the Management of PPHN? Alveolar, Arterial, Mixed Venous Oxygen Tension or Peripheral Saturation?
}

\author{
Praveen Chandrasekharan ${ }^{1, *(\mathbb{D})}$, Munmun Rawat ${ }^{1}$ (D) and Satyan Lakshminrusimha ${ }^{2} \mathbb{C}$ \\ 1 Division of Neonatology, Department of Pediatrics, University at Buffalo, Buffalo, NY 14260, USA; \\ munmun.rawat@gmail.com \\ 2 Division of Neonatology, Department of Pediatrics, University of California Davis, Davis, CA 95616, USA; \\ slakshmi@ucdavis.edu \\ * Correspondence: pkchandr@buffalo.edu
}

Received: 18 August 2020; Accepted: 11 October 2020; Published: 13 October 2020

\begin{abstract}
Oxygen is a pulmonary vasodilator and plays an important role in mediating circulatory transition from fetal to postnatal period. Oxygen tension $\left(\mathrm{PO}_{2}\right)$ in the alveolus $\left(\mathrm{PAO}_{2}\right)$ and pulmonary artery $\left(\mathrm{PaO}_{2}\right)$ are the main factors that influence hypoxic pulmonary vasoconstriction (HPV). Inability to achieve adequate pulmonary vasodilation at birth leads to persistent pulmonary hypertension of the newborn (PPHN). Supplemental oxygen therapy is the mainstay of PPHN management. However, optimal monitoring and targeting of oxygenation to achieve low pulmonary vascular resistance (PVR) and optimizing oxygen delivery to vital organs remains unknown. Noninvasive pulse oximetry measures peripheral saturations $\left(\mathrm{SpO}_{2}\right)$ and a target range of $91-95 \%$ are recommended during acute PPHN management. However, for a given $\mathrm{SpO}_{2}$, there is wide variability in arterial $\mathrm{PaO}_{2}$, especially with variations in hemoglobin type ( $\mathrm{HbF}$ or $\mathrm{HbA}$ due to transfusions), $\mathrm{pH}$ and body temperature. This review evaluates the role of alveolar, preductal, postductal, mixed venous $\mathrm{PO}_{2}$, and $\mathrm{SpO}_{2}$ in the management of $\mathrm{PPHN}$. Translational and clinical studies suggest maintaining a $\mathrm{PaO}_{2}$ of $50-80 \mathrm{mmHg}$ decreases PVR and augments pulmonary vasodilator management. Nevertheless, there are no randomized clinical trials evaluating outcomes in PPHN targeting $\mathrm{SpO}_{2}$ or $\mathrm{PO}_{2}$. Also, most critically ill patients have umbilical arterial catheters and postductal $\mathrm{PaO}_{2}$ may not be an accurate assessment of oxygen delivery to vital organs or factors influencing HPV. The mixed venous oxygen tension from umbilical venous catheter blood gas may assess pulmonary arterial $\mathrm{PO}_{2}$ and potentially predict HPV. It is crucial to conduct randomized controlled studies with different $\mathrm{PO}_{2} / \mathrm{SpO}_{2}$ target ranges for the management of PPHN and compare outcomes.
\end{abstract}

Keywords: oxygenation; PPHN; oxygen tension

\section{Introduction}

Persistent pulmonary hypertension of the newborn (PPHN) occurs when there is impaired pulmonary vascular transition during birth due to disruption of pulmonary vasodilator mechanisms. Impaired transition from fetal to neonatal circulation leads to elevated pulmonary vascular resistance (PVR), right-to-left or bidirectional shunts at patent foramen ovale (PFO) and/or patent ductus arteriosus (PDA) leading to hypoxemia [1]. Both term and preterm neonates are at risk for PPHN [2-5]. The course of preterm neonates in the neonatal intensive care unit (NICU) is further complicated by the development of bronchopulmonary dysplasia (BPD) and can potentially be associated with pulmonary hypertension (PHT) [6-8]. The incidence of PPHN in neonates are often underestimated but is thought to be around 1.8 to 2/1000 live births [1,5,9]. In infants with PPHN, several studies report poor 
long-term neurodevelopment outcomes and higher early mortality rates despite pulmonary vasodilator therapies $[1,10,11]$. At birth, with the initiation of spontaneous breathing or with positive pressure ventilation (PPV) and with adequate lung inflation, the pulmonary blood flow (PBF) increases by 8 to 10 -fold along with a decrease in PVR. As the fetus grows in a relatively hypoxemic environment, increase in oxygen tension seems to play a significant role in decreasing PVR at birth [12]. Optimal oxygenation is necessary to meet tissue demand, especially in vital organs such as brain and heart and to prevent hypoxic pulmonary vasoconstriction (HPV). This review discusses the role of oxygen tension $\left(\mathrm{PO}_{2}\right)$ and pulse oximetry $\left(\mathrm{SpO}_{2}\right)$ during the management of PPHN. With lack of clinical evidence on optimal oxygenation in PPHN, this manuscript reviews data from both term and preterm translational models associated with high PVR in the perinatal period.

\section{Discussion}

Understanding the relationship of fetal oxygenation, PVR, pulmonary blood flow (PBF) in both the fetus and newborn is critical to managing a neonate with PPHN.

\subsection{Relation of $\mathrm{PO}_{2}$ and Fetal PVR}

The fetus develops with placenta serving as an organ of gas exchange. The highest $\mathrm{PO}_{2}$ within the fetal circulation is approximately $32-35 \mathrm{mmHg}$ in the umbilical vein. There is a further decrease in $\mathrm{PO}_{2}$ to $25-28 \mathrm{mmHg}$ in the ascending aorta supplying the developing brain and myocardium [13-15]. The placenta protects the fetus from maternal hyperoxia and hypoxia [14,15]. As observed in translational studies, during maternal hyperoxia/hypoxia, the distribution of blood in the placenta, channeling of blood to and from the fetal liver by ductus venosus, and alteration of PVR (increase/decrease) avoids excessive fluctuations in fetal $\mathrm{PO}_{2}$ [16]. The relationship of fetal $\mathrm{PVR}$ to $\mathrm{PO}_{2}$ is dependent on the gestational age (GA) of the fetus [17]. By term gestation, PVR decreases dramatically in response to increased fetal $\mathrm{PO}_{2}$ [18].

\subsection{Gestational Age, Fetal $P V R$, and $\mathrm{PO}_{2}$}

The changes in PVR to $\mathrm{PO}_{2}$ in relation to GA were studied in fetal ovine model [19]. Ovine fetuses at different GA of 0.6 (103-104/term 150 days), 0.74 (112-119 days), 0.80 (121-130 days), and 0.90 (132-138 days) were exposed to hypoxia or hyperoxia by adjusting the oxygen exposure to the ewe. Pulmonary vasoconstriction and vasodilation were observed at term gestation when exposed to low and high $\mathrm{PO}_{2}$. Hypoxia and hyperoxia did not have a significant effect on PVR at 0.6 and 0.74 gestation. In humans, maternal hyperoxia did not alter fetal PBF at 20-26 weeks GA but increased PBF and reduced atrial and ductal shunting at 31 to 36 weeks [20]. Extrapolating from these findings, the pulmonary vascular response to $\mathrm{PO}_{2}$ seems to increase with advancing gestational age.

\subsection{Effect of $\mathrm{PO}_{2}$ on $\mathrm{PVR}$ at Birth}

During normal transition, spontaneous breath initiated by the newborn infant ventilates the lung and increases alveolar oxygen tension, which increases PBF reducing PVR, successfully switching from fetal to neonatal circulation [21]. Multiple factors such as mode of delivery (vaginal delivery results in more rapid reduction in PVR compared to an elective cesarean section), maturity, antenatal glucocorticoids, temperature (hypothermia increases PVR), mode of cord clamping and asphyxia (related to higher PVR), could affect transition at birth [22]. These factors affect the balance between the vasoconstrictors (endothelin-1, thromboxane), and vasodilators (prostacyclin and endothelium derived nitric oxide), which exert their effects on the pulmonary artery smooth muscle cells (PASMC). In addition to these factors, oxygen $\left(\mathrm{O}_{2}\right)$ seems to play a greater role in the regulation of PVR by having a direct effect on PASMC. Oxygen stimulates the increased production of pulmonary endothelial nitric oxide (NO), which is a potent pulmonary vasodilator birth [22]. 


\subsection{Oxygen and Hypoxic Pulmonary Vasoconstriction (HPV)}

A fundamental difference between pulmonary blood vessels and systemic vessels is their ability to constrict in response to hypoxia [23]. Regional HPV diverts blood away from underventilated alveoli and promotes ventilation-perfusion $(\mathrm{V} / \mathrm{Q})$ matching. $\mathrm{HPV}$ is mediated by $\mathrm{PO}_{2}$ surrounding the precapillary pulmonary arteriole (Figure 1 ) and is influenced both by mixed venous (pulmonary arterial) $\mathrm{PVO}_{2}$ and alveolar $\mathrm{PAO}_{2}$ [24]. The stimulus for HPV is dictated by the equation $\mathrm{P}$ (stimulus) $\mathrm{O}_{2}=\mathrm{PVO}_{2}{ }^{0.375} \times \mathrm{PAO}_{2}{ }^{0.626}$. Based on this equation, it is clear that alveolar $\mathrm{PAO}_{2}$ is the predominant factor determining the severity of HPV. Acidosis exacerbates HPV in neonatal animal models [15].

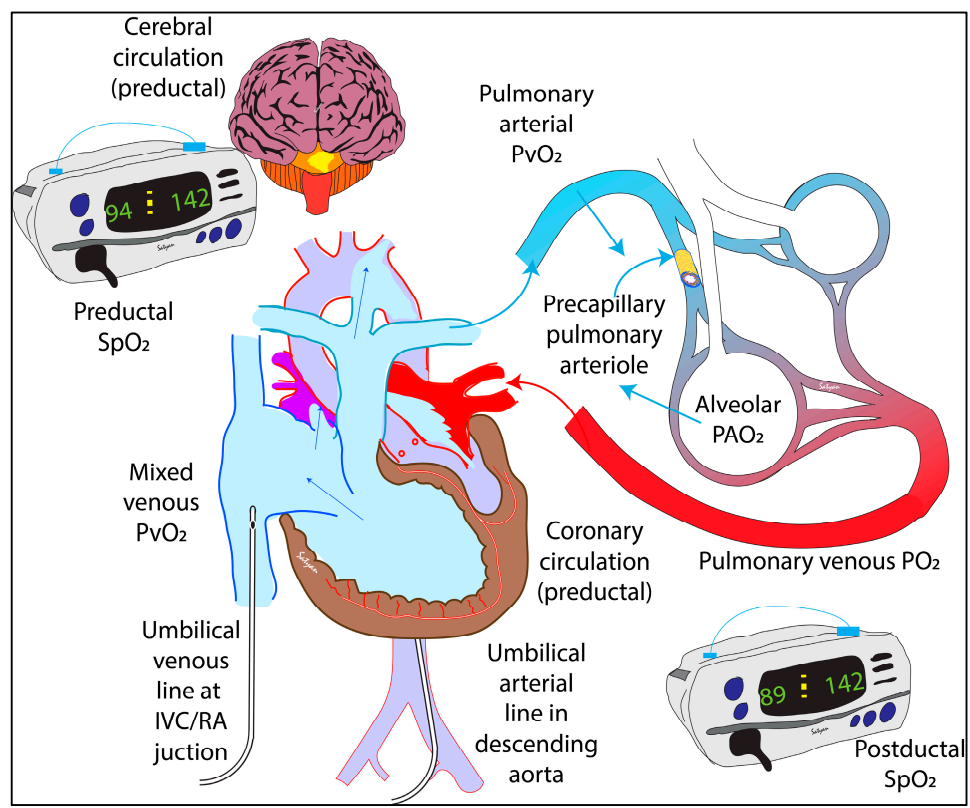

Figure 1. The primary determinant of hypoxic pulmonary vasoconstriction is the precapillary pulmonary arteriole. The oxygen tension at this site is determined by alveolar $\mathrm{PAO}_{2}$ and pulmonary arterial $\mathrm{PO}_{2}$. In the absence of lung disease, pulmonary venous $\mathrm{PO}_{2}$ and alveolar $\mathrm{PAO}_{2}$ are usually similar. In the absence of significant shunts, preductal $\mathrm{PaO}_{2}$ is reflective of pulmonary venous $\mathrm{PO}_{2}$. Umbilical venous $\mathrm{PO}_{2}$ is similar to mixed venous $\mathrm{PO}_{2}$ and pulmonary arterial $\mathrm{PO}_{2}$ in the absence of a left-to-right atrial/ductal shunt. Oxygen delivery to the brain and heart is based on preductal $\mathrm{PaO}_{2}$ and $\mathrm{SpO}_{2}$. Postductal $\mathrm{PaO}_{2}$ (from an umbilical arterial line) can be low and does not predict PVR or oxygen delivery to vital organs. Copyright Satyan Lakshminrusimha.

\subsection{Supplemental Oxygen and $\mathrm{PO}_{2}$ during the Transition}

Oxygen supplementation is the most common resuscitative measure for newborns in the delivery room. American Academy of Pediatrics Neonatal Resuscitation Program (AAP NRP) recommends that supplemental $\mathrm{O}_{2}$ be initiated at concentrations of $21 \% \mathrm{O}_{2}$ in term and $21-30 \% \mathrm{O}_{2}$ in preterm neonates and to titrate based on prespecified preductal saturations [25]. Given the ease and universal use of pulse oximetry, preductal oxygen saturations $\left(\mathrm{SpO}_{2}\right)$ could be the most efficient way of targeting oxygenation in the delivery room and the neonatal intensive care unit (NICU). However, for a given saturation range, the achieved $\mathrm{PO}_{2}$ could vary widely and the extremes of $\mathrm{SpO}_{2}$ have low accuracy [26]. In a newborn requiring resuscitation, hypoperfusion could also decrease the accuracy of $\mathrm{SpO}_{2}$.

\subsection{Oxygen Tension in Spontaneous Air Breathing Infants}

The concept of normoxemia in a transitioning newborn is not well defined. A healthy newborn, who transitioned from placenta to lungs as an organ of gas exchange, sees a rise in arterial oxygen tension $\left(\mathrm{PaO}_{2}\right)$ by $30-40 \mathrm{mmHg}$ from fetal values. The increases in alveolar $\mathrm{PAO}_{2}$ and arterial $\mathrm{PaO}_{2}$ 
along with ventilation play an important role in decreasing PVR and increasing PBF. In a study of near term gestation lambs (comparable to human term neonates), the use of $21 \% \mathrm{O}_{2}$ lead to $\mathrm{PaO}_{2}$ values of 50-60 mmHg [12]. The observed decrease in PVR from fetal life occurred at a $\mathrm{PaO}_{2}$ of $52.5 \pm 1.7 \mathrm{mmHg}$, also known as the change point [12]. The change point is the $\mathrm{PaO}_{2}$ value at which there is a change in the slope of $\mathrm{PVR}-\mathrm{PaO}_{2}$ scatter plot. In human neonates, who were previously on respiratory support and were weaned to room air and breathing spontaneously, 176 samples of arterial blood gas were analyzed [27]. The analysis showed that $80 \%$ of the $\mathrm{PaO}_{2}$ values were between $40-80 \mathrm{mmHg}$ and the average $\mathrm{PaO}_{2}$ was $64 \mathrm{mmHg}$. In a study involving 10 neonates, the average $\mathrm{PaO}_{2}$ was $77 \pm 4.5 \mathrm{mmHg}$ in quiet asleep compared to a $\mathrm{PaO}_{2}$ of $70 \pm 6.5 \mathrm{mmHg}$ in active sleep [28]. In this study, the quiet sleep was defined as no eye movement or activity, while active sleep had frequent small movements, and the site of blood draw (pre vs. post ductal) is not known [28]. A recent study, defined normoxemia in neonates with a $\mathrm{PaO}_{2}$ range of $50-80 \mathrm{mmHg}$ [29]. Based on these observations, the $\mathrm{PaO}_{2}$ in normal neonates mostly ranges between $50-80 \mathrm{mmHg}$. Achieving a similar preductal $\mathrm{PaO}_{2}$ value during the management of PPHN neonates appears prudent.

\subsection{Oxygen Tension and PPHN}

In a neonate with PPHN secondary to failed transition or underlying lung pathology, the elevated pulmonary pressures often lead to shunting of blood from pulmonary to the systemic circulation, leading to profound and labile hypoxemia despite PPV and supplemental oxygen. Adequate oxygenation to achieve preductal $\mathrm{PaO}_{2}$ in the $50-80 \mathrm{mmHg}$ range (similar to normal neonates) remains the cornerstone of PPHN management in both term and preterm neonates.

\subsection{Alveolar $\mathrm{PAO}_{2}$ and its Effect on PPHN}

The alveolar $\mathrm{PO}_{2}\left(\mathrm{PAO}_{2}\right)$, which can be calculated using the inspired $\mathrm{O}_{2}$ concentration and arterial oxygenation and carbon dioxide tension, is a major determinant of HPV [30]. In the presence of parenchymal lung injury and or immature lungs, alveolar hypoxia could exacerbate pulmonary vasoconstriction. Studies done four decades ago, comparing newborn and adult ovine models, have shown that alveolar hypoxia leads to more significant HPV leading to redistribution of pulmonary circulation away from hypoxic lung in newborn lambs compared to adult sheep (Figure 2).

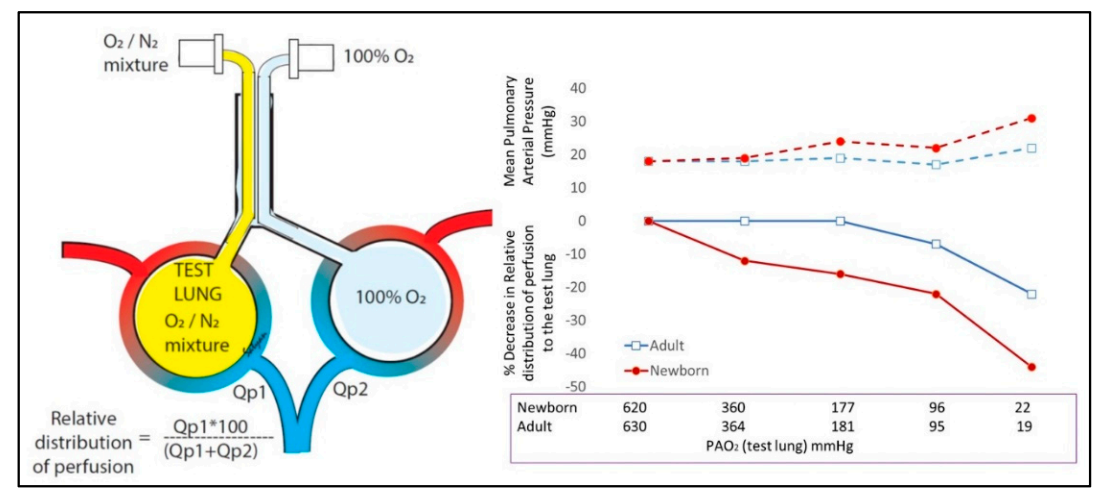

Figure 2. Created using data from Custer et al. [31]. Importance of alveolar hypoxia in directing lung blood flow. Neonatal lambs and adult sheep were instrumented. Each lung was intubated with a different endotracheal tube. One lung was ventilated with $100 \%$ oxygen and the other test lung with varying concentrations of oxygen mixed with nitrogen. Relative distribution of perfusion was calculated with Qp1 (blood flow to test lung) and Qp2 (blood flow to the 100\% oxygen lung) using the formula shown in the figure. Lower $\mathrm{PAO}_{2}$ had a profound effect on pulmonary vasoconstriction in newborn ovine model (red line) compared to adults (blue line).

In adult sheep, alveolar $\mathrm{PAO}_{2}$ had to drop to $19 \mathrm{mmHg}$ to observe significant redistribution of blood flow away from the hypoxic lung. In sharp contrast, reduction of alveolar $\mathrm{PAO}_{2}$ below 
$360 \mathrm{mmHg}$ (equivalent to ventilation with $50 \%$ oxygen), lead to HPV and redistribution of blood away from the hypoxic lung (Figure 2).

However, HPV occurred only with severe alveolar hypoxia in adult lambs exacerbating ventilation-perfusion mismatch [31]. These results suggest that HPV in response to alveolar hypoxia is more prominent and severe, and occurs at higher $\mathrm{PAO}_{2}$ levels during the neonatal period compared to adult life.

Table 1 shows the effect of inspired oxygen concentration on preductal arterial $\left(\mathrm{PaO}_{2}\right), \mathrm{PVR}$ and alveolar $\mathrm{PAO}_{2}$ (calculated using $\mathrm{PaCO}_{2}$ ), in control term gestation lambs and lambs with $\mathrm{PPHN}$ induced by antenatal ductal ligation (a model of primary PPHN without any lung disease). [12] In control lambs without lung disease or PPHN, low PVR is achieved by ventilation with $21 \%$ oxygen with alveolar $\mathrm{PAO}_{2}$ in the $90-100 \mathrm{mmHg}$ range.

Table 1. Effect of $\mathrm{PAO}_{2}$ on control and PPHN ovine models on PVR [12]

\begin{tabular}{cccccc}
\hline Parameters & $\mathbf{O}_{\mathbf{2}}(\mathbf{\%})$ & $\mathbf{P a C O}_{\mathbf{2}}(\mathbf{m m H g})^{*}$ & $\mathbf{P a O}_{\mathbf{2}}(\mathbf{m m ~ H g}){ }^{*}$ & $\begin{array}{c}\mathbf{P V R} \\
(\mathbf{m m H g} / \mathbf{m L} / \mathbf{k g} / \mathbf{m i n})\end{array}$ & $\begin{array}{c}\mathbf{P A O}_{\mathbf{2}}(\mathbf{m m H g}) \\
\mathbf{C a l c u l a t e d}\end{array}$ \\
\hline Control & 21 & $42 \pm 2$ & $57 \pm 6$ & $0.28 \pm 0.01$ & $94.5 \pm 6.2$ \\
PPHN & 21 & $44 \pm 3$ & $23 \pm 2$ & $1.6 \pm 0.2$ & $92.0 \pm 5.3$ \\
PPHN & 50 & $39 \pm 3$ & $36 \pm 8$ & $1.0 \pm 0.1$ & $301.3 \pm 11.3$ \\
PPHN & 100 & $47 \pm 5$ & $40 \pm 5$ & $1.0 \pm 0.1$ & $641.3 \pm 10.5$ \\
\hline
\end{tabular}

* Mean and standard error of mean.

However, in lambs with PPHN, use of $21 \%$ oxygen leads to normal $\mathrm{PAO}_{2}$ but low $\mathrm{PaO}_{2}$ compared to non-PPHN controls, and is associated with high PVR. Increasing calculated $\mathrm{PAO}_{2}$ by increasing inspired oxygen led to a decrease in PVR (Table 1) [12]. In this model of primary PPHN, inspired oxygen concentration of $50 \%$ was needed to elicit maximal decrease in PVR. Although alveolar hypoxia worsens PPHN, hyperoxia $\left(\mathrm{PAO}_{2}>300 \mathrm{mmHg}\right)$ did not have any additional vasodilator effect. Pulmonary vasodilator response to hyperoxia may not be sustained and could blunt the vasodilator response to inhaled nitric oxide (iNO) [32]. A concern with alveolar $\mathrm{PAO}_{2}$ is that it is calculated using mathematical equations and in heterogenous lung disease, different areas of the lung may have different $\mathrm{PAO}_{2}$ values.

In an acute meconium aspiration model of ovine $\mathrm{PPHN}, \mathrm{SpO}_{2}$ range of $90-94 \%$ was associated with an increase in $\mathrm{PaO}_{2}$ alone without an increase in $\mathrm{PAO}_{2}$ and resulted in a marginal improvement in PVR and PBF. At $\mathrm{SpO}_{2}$ of $93-97 \%$ an increase in both $\mathrm{PaO}_{2}$ and $\mathrm{PAO}_{2}$ were necessary to achieve optimal decrease in PVR (Figure 3). With the high prevalence of PHT among extremely preterm infants, it is critical to understand the role of $\mathrm{PAO}_{2}$ in regulating PVR [33]. Kinsella et al. evaluated the pulmonary vasodilator effect of iNO, oxygen and lung distension on developing pulmonary circulation [34]. In preterm lambs at 115 days GA ( 0.78 of term), pulmonary vasodilation was more prominent with rhythmic lung distension compared to supplemental oxygen or iNO [34]. In near term lambs, $100 \%$ oxygen and iNO led to profound pulmonary vasodilation [34]. We speculate that in the setting of extreme prematurity and respiratory distress syndrome in the absence of classic PPHN physiology, iNO and alveolar hyperoxia may not be effective in decreasing PVR compared to term neonates.

\subsection{Arterial Oxygen Tension and Its Effect on PPHN}

Preductal arterial oxygenation $\left(\mathrm{PaO}_{2}\right)$ is typically used to assess the severity (based on oxygenation index), management, and evaluate response to therapy in PPHN [35]. In neonates with PPHN treated with adequate ventilation and supplemental oxygen, a preductal $\mathrm{PaO}_{2}$ of $<40 \mathrm{mmHg}$ reflects hypoxemia. Secondary to right-to-left shunting across the ductus, there may be a pre and post ductal difference in $\mathrm{SpO}_{2}$ and $\mathrm{PaO}_{2}$. No clinical studies to date have studied the effect of maintaining various levels of $\mathrm{PaO}_{2}$ in the management of PPHN. As mentioned previously, a preductal $\mathrm{PaO}_{2}$ of $>52.5 \pm 1.7 \mathrm{mmHg}$ decreased PVR in ovine models without PPHN, while a $\mathrm{PaO}_{2}$ of $>59.6 \pm 15.3 \mathrm{mmHg}$ was required to decrease PVR in a PPHN model [12]. In a preterm RDS model, a $\mathrm{PaO}_{2}$ of $>58 \mathrm{mmHg}$ was required to 
decrease in PVR [17]. Similarly, the change point for preductal $\mathrm{PaO}_{2}$ was $45 \pm 0.1 \mathrm{mmHg}$ in a model of asphyxia with meconium aspiration syndrome.

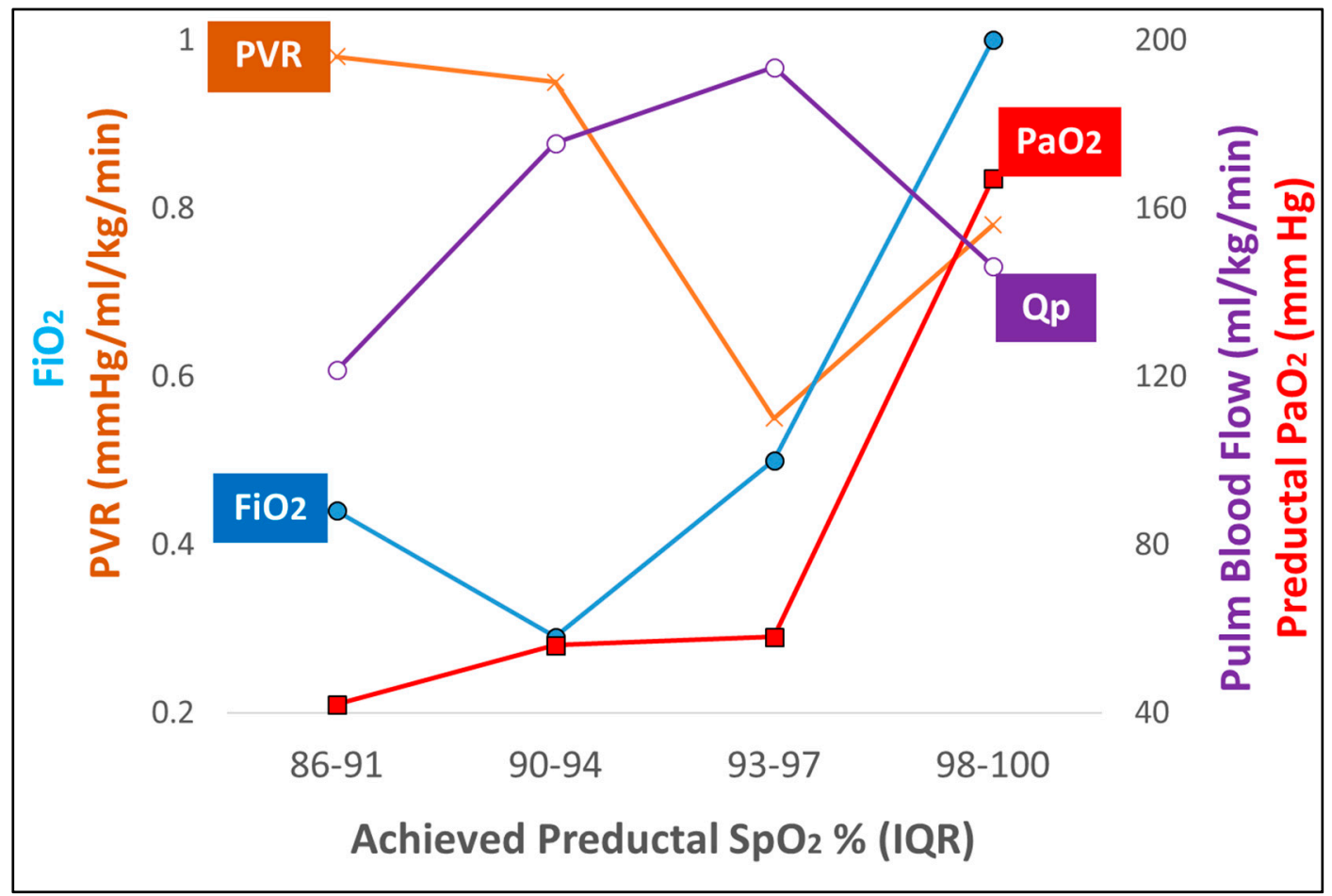

Figure 3. A graph depicting the relationship of inspired oxygen, PVR, left pulmonary blood flow, arterial oxygenation and preductal $\mathrm{SpO}_{2}$ is illustrated in an ovine model of meconium aspiration model with PPHN. [36] The pulmonary vascular resistance (PVR—brown cross), pulmonary blood flow (Qp-purple open circles), $\mathrm{FiO}_{2}$ (blue circles) and $\mathrm{PaO}_{2}$ (red squares) at different preductal saturation $\left(\mathrm{SpO}_{2}\right)$ ranges are shown. Preductal $\mathrm{SpO}_{2}$ in high $80 \mathrm{~s}$ resulted in high PVR and low Qp. Preductal $\mathrm{SpO}_{2}$ in the low-90 s was associated with increased $\mathrm{PaO}_{2}$, increased Qp, low $\mathrm{FiO}_{2}$ and high PVR (due to high pulmonary arterial pressure-not shown). Preductal $\mathrm{SpO}_{2}$ in the mid-90 s was associated with $\mathrm{FiO}_{2}$ in the 0.5 range with lowest PVR, highest Qp in this model. Increasing $\mathrm{FiO}_{2}$ to 1.0 increased $\mathrm{PaO}_{2}$ and $\mathrm{SpO}_{2}$ but did not result in further increase in Qp or decrease in PVR. For detailed statistical analysis, please refer to Rawat et al. [36]. Copyright Satyan Lakshminrusimha.

Recently, we have shown that in a model of asphyxia and meconium aspiration with PPHN during the first $6 \mathrm{~h}$ post-resuscitation, targeting a preductal $\mathrm{SpO}_{2}$ of $95-99 \%$ and achieving 93-97\% $\mathrm{SpO}_{2}$ with a corresponding $\mathrm{PaO}_{2}$ of $58 \pm 19 \mathrm{mmHg}$ was associated with the lowest PVR $(0.55 \pm 0.15 \mathrm{mmHg} / \mathrm{mL} / \mathrm{kg} / \mathrm{min})$, with an inspired oxygen requirement of $50 \pm 21 \%$ [36]. In this study, the $\mathrm{SpO}_{2}$ range of $90-94 \%$ had a similar $\mathrm{PaO}_{2}(56 \pm 11 \mathrm{mmHg})$, but the corresponding PVR was much higher with a significantly lower inspired oxygen requirement $(29 \pm 17 \%)$ [36]. These results shown in Figure 3 outline the importance of alveolar $\mathrm{PAO}_{2}$ in addition to arterial $\mathrm{PaO}_{2}$ in mediating lower PVR. While the $\mathrm{PaO}_{2}$ in the $90-94 \% \mathrm{SpO}_{2}$ group and $93-97 \% \mathrm{SpO}_{2}$ group were identical, we speculate that the difference in $\mathrm{FiO}_{2}$ contributed to the marked decrease in PVR in the 93-97\% group (Figure 3).

With the available data, preductal $\mathrm{PaO}_{2}$ has a high utility in neonates with PPHN as it dictates the amount of oxygen delivered to the cerebral and coronary circulation. In summary, targeting preductal arterial oxygenation in the clinically accepted range of normoxemia $(50-80 \mathrm{mmHg}$ ), could help in managing PPHN by optimizing oxygen delivery, but is not the only factor determining PVR. Providing adequate $\mathrm{FiO}_{2}$ to maintain optimal alveolar $\mathrm{PAO}_{2}$ is also important in mediating pulmonary vasodilation. Avoiding extremely high $\mathrm{PaO}_{2}(>100 \mathrm{mmHg})$ and $\mathrm{PAO}_{2}(>300 \mathrm{mmHg})$ may potentially facilitate response to other pulmonary vasodilators, reducing high cumulative oxygen exposure and 
toxicity $[12,30,32]$. The optimal $\mathrm{PaO}_{2}$ range during acute phase of PPHN warrants further clinical trials focusing on both short-term and long-term outcomes.

\section{Post-Ductal $\mathrm{PaO}_{2}\left(\mathrm{PDPaO}_{2}\right)$ and PPHN}

Given the easy arterial access path in neonates, a high umbilical arterial catheter (UAC), with its tip in the thoracic portion of the descending aorta, is the most commonly placed arterial access in the NICU [37]. When blood gas is obtained from the UAC, it usually reflects post-ductal $\left(\mathrm{PDPaO}_{2}\right)$ unless the ductus arteriosus is closed (Figure 1) [35]. Labile hypoxemia, in the presence of shunting from pulmonary to systemic circulation, could present with pre and post ductal $\mathrm{PaO}_{2}$ gradient of $10-20 \mathrm{mmHg}$, which often goes in hand with pre and post ductal $\mathrm{SpO}_{2}$ difference and is characteristic of PPHN. In the absence of shunting, a $\mathrm{PDPaO}_{2}$ could reflect preductal $\mathrm{PaO}_{2}$. In a clinical trial comparing the blood gas to saturation values, out of 800 arterial blood gas samples collected, $88 \%$ of the samples were postductal, which reflects the extensive use of $\mathrm{PDPaO}_{2}$ to evaluate and guide therapy when supplemental oxygen is needed [27]. Using preductal $\mathrm{SpO}_{2}$ to adjust $\mathrm{FiO}_{2}$ is preferred to the use of $\mathrm{PDPaO}_{2}$ during management of PPHN. However, absence of a preductal to postductal oxygenation gradient does not rule out bidirectional ductal shunting and low PBF [35].

\subsection{Mixed Venous Oxygen Tension $\left(\mathrm{PvO}_{2}\right)$ and Management of PPHN}

The mixed venous $\mathrm{PO}_{2}$ typically refers to oxygen tension in the pulmonary artery [38]. Since umbilical venous catheters (UVC) are commonly placed in the NICU, the blood gas obtained from a UVC is used as a proxy for mixed venous gas [39]. The $\mathrm{PVO}_{2}$ could assess the tissue oxygenation in neonates.

In a clinical study involving 22 neonates with respiratory failure requiring mechanical ventilation, $\mathrm{PVO}_{2}$ had an inverse relationship with arterial-venous oxygen content difference $(\mathrm{r}=-0.528)$ and fractional oxygen extraction ( $r=-0.592)$. The position of UVC (high in the right atrium or near PFO vs. low in the inferior vena cava) could affect the $\mathrm{PVO}_{2}$ measurements and may not accurately reflect the pulmonary arterial $\mathrm{PO}_{2}$ especially if they are also being used to infuse fluids.

In our lab, in a meconium aspiration model and a preterm RDS model, a $\mathrm{PVO}_{2}$ demonstrated a change point of 25 and $32 \mathrm{mmHg}$ respectively [40,41] (Figure 4). The utility of $\mathrm{PVO}_{2}$ from the UVC during the management of PPHN requires further exploration.

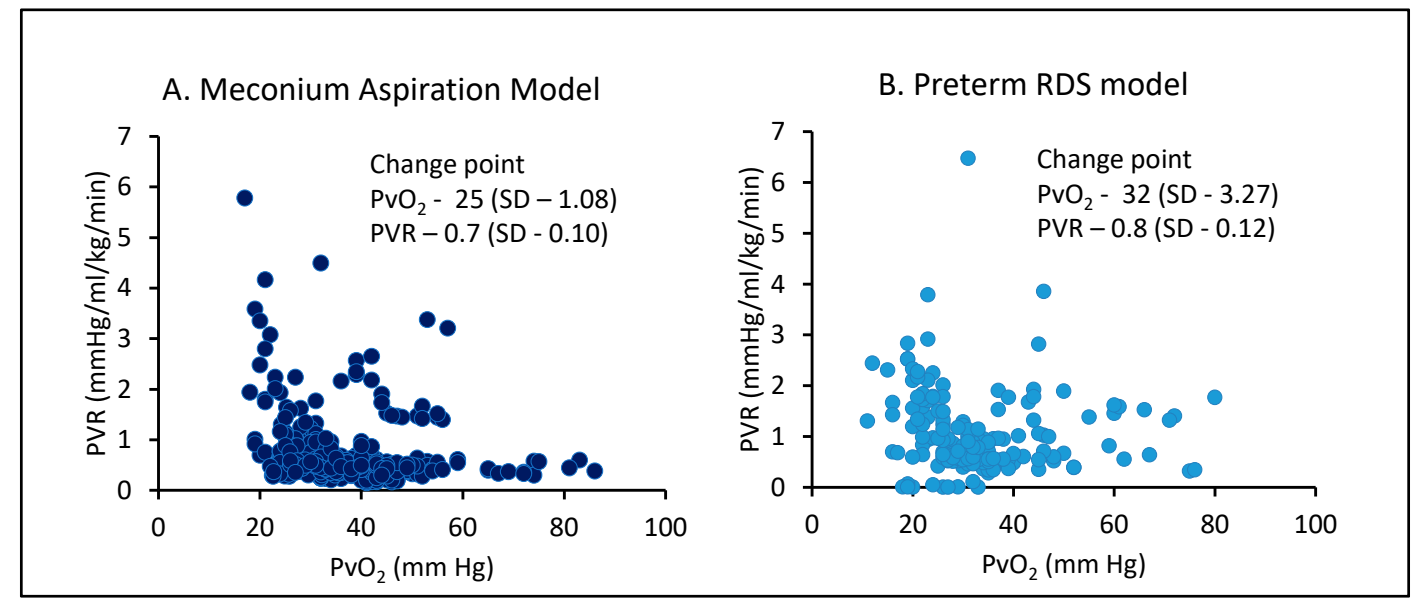

Figure 4. The scatterplot between PVR and $\mathrm{PVO}_{2}$ is shown in (A) meconium aspiration model and (B) preterm RDS model. The $\mathrm{PVO}_{2}$ was obtained from the main pulmonary artery blood gas. The MCMC model using SAS 9.4 (NC) estimated change point. Copyright MR/PC/SL.

\subsection{Effect of Transfusion, $p H$ and Temperature on Relationship between $\mathrm{SpO}_{2}$ and $\mathrm{PaO}_{2}$ in $\mathrm{PPHN}$}

The influence of transfusion, temperature and acidity $(\mathrm{pH})$ on $\mathrm{SpO}_{2}$ and $\mathrm{PaO}_{2}$ could be explained by oxygen dissociation curve. Oxygen dissociation curve (ODC) explains the relationship between 
oxygen saturation of the hemoglobin (plotted in $y$-axis) and oxygen tension (plotted in $x$-axis), which is essential for oxygen absorption in the lungs and delivery to the tissues [42]. A right shift in the curve is associated with release of $\mathrm{O}_{2}$ to the tissues and a left shift is associated with $\mathrm{O}_{2}$ absorption from the lungs. Fetal hemoglobin $(\mathrm{HbF})$ is the predominant type during fetal and neonatal period. Secondary to high affinity of $\mathrm{HbF}$ to $\mathrm{O}_{2}$ the ODC is shifted to the left in neonates and this could lead to higher oxygen saturation for lower $\mathrm{PaO}_{2}$. Thus, for a $\mathrm{PaO}_{2}$ of approximately $40 \mathrm{mmHg}$, the $\mathrm{SpO}_{2}$ could be between $85-93 \%$, and for a $\mathrm{SpO}_{2}$ of $97 \%$ the $\mathrm{PaO}_{2}$ could be $>100 \mathrm{~mm} \mathrm{Hg}$ [27]. Factors such as blood transfusions affect the ODC. The packed red blood cell transfusion that predominantly has $\mathrm{HbA}$ (adult hemoglobin), could alter the oxygen affinity moving the ODC to the right affecting the relation between $\mathrm{SpO}_{2}$ and $\mathrm{PaO}_{2}$ [42]. PPHN, respiratory failure and carbon dioxide retention with low $\mathrm{pH}$ could move the ODC right with lower affinity of $\mathrm{Hb}$ to $\mathrm{O}_{2}$, which affects the $\mathrm{SpO}_{2}$ for a given $\mathrm{PaO}_{2}$. Lastly, temperature affects the blood gas analysis unless the values are corrected for body temperature [43].

The solubility of a gas increases with lower temperature and it is important to analyze blood gas and correct it for body temperature. In infants undergoing whole body hypothermia for moderate to severe hypoxic ischemic encephalopathy (HIE), periodic assessment of $\mathrm{PaO}_{2}$ corrected for body temperature is important to avoid hypoxia and exacerbation of PPHN. Uncorrected $\mathrm{PaO}_{2}$ and $\mathrm{SpO}_{2}$ may not be reliable and targeting these values could potentially lead to hypoxemia during whole body hypothermia as shown in Figure 5 [43]. Thus, it is important that blood transfusions, $\mathrm{pH}$ and temperature be taken into account while managing an infant with PPHN. Periodically checking arterial blood gases and trying to maintain preductal $\mathrm{PaO}_{2}$ in the $50-80 \mathrm{mmHg}$ range may be beneficial in the management of PPHN by avoiding HPV.

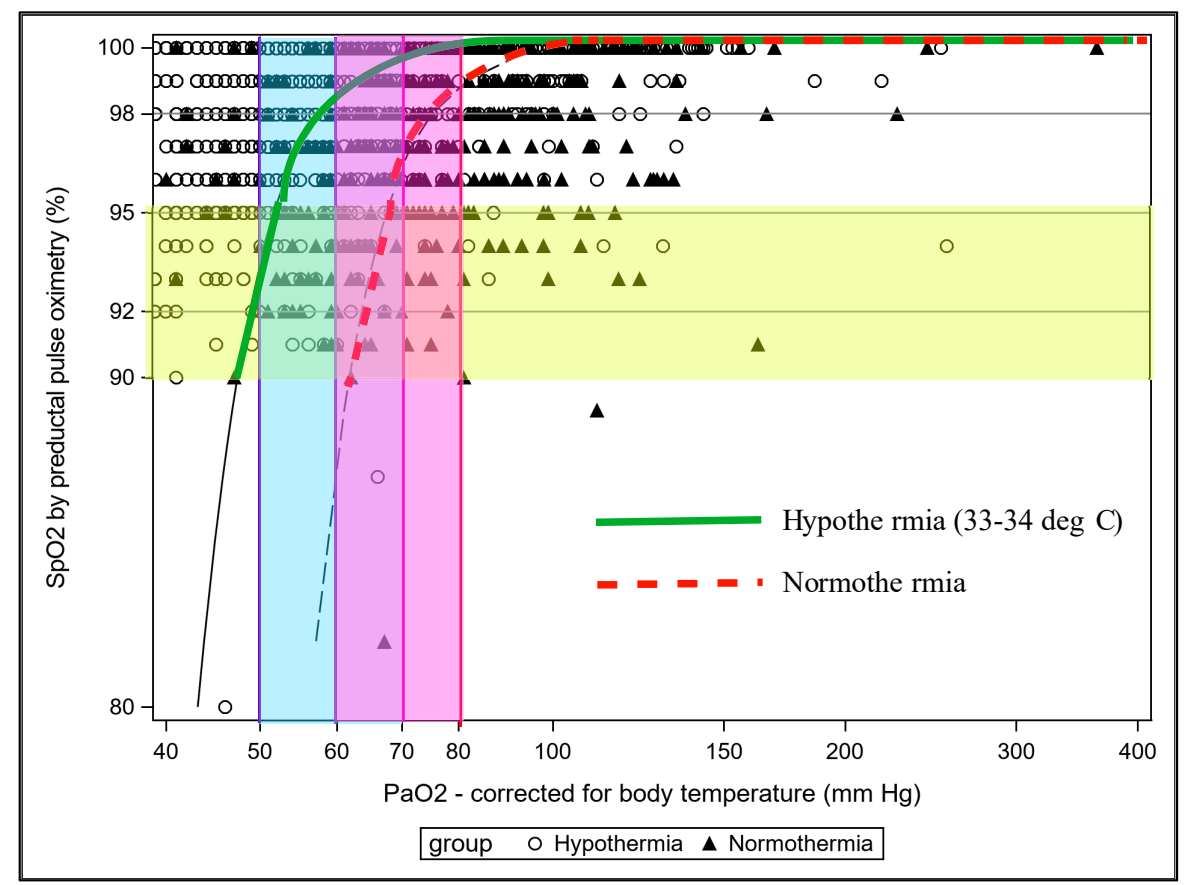

Figure 5. The relation between $\mathrm{SpO}_{2}$ (y-axis) and $\mathrm{PaO}_{2}$ ( $x$-axis) in hypothermia and normothermia is shown. In normothermia and hypothermia, the relationship between $\mathrm{SpO}_{2}$ and $\mathrm{PaO}_{2}$ is altered. Targeting a preductal corrected $\mathrm{PaO}_{2}$ of $50-80 \mathrm{mmHg}$ may require preductal $\mathrm{SpO}_{2}$ in the mid- to high $90 \mathrm{~s}$ during management of severe PPHN on whole body hypothermia. Copyright Satyan Lakshminrusimha.

\section{Conclusions}

In the management of PPHN, arterial oxygen tension plays an essential role in establishing the diagnosis, assessing the severity, guiding treatment, facilitating specific pulmonary vasodilator therapy, evaluating the response to therapy, and escalating care if needed. Since an UAC placement is standard 
of care, the disadvantage of having $\mathrm{PDPaO}_{2}$ could be a limitation, especially in severe PPHN with labile hypoxemia with ductal shunts. Preductal oxygenation dictates oxygen delivery to brain and heart. Hypoxic pulmonary vasoconstriction is associated with low alveolar oxygen tension and mixed venous oxygen tension. While $\mathrm{SpO}_{2}$ provides a continuous, non-invasive assessment of preductal oxygenation, periodic blood gas evaluation is warranted especially in the presence of hypothermia or acidosis. Further clinical trials are warranted to assess the utility of preductal, postductal, and umbilical venous $\mathrm{PO}_{2}$ in addition to preductal $\mathrm{SpO}_{2}$ in the management of $\mathrm{PPHN}$.

Author Contributions: P.C. conceptualized, wrote the first draft, reviewed revised, provided data from RDS model, did the statistical analysis and accepted the final draft. M.R. conceptualized, provided data and calculations from meconium aspiration model with PPHN, reviewed, revised and accepted the final draft. S.L. conceptualized, provided data from PPHN model, hypothermia model, reviewed, revised and accepted the final draft. All authors have read and agreed to the published version of the manuscript.

Funding: This research was funded by Eunice Kennedy Shriver National Institute of Child Health and Human Development, grant number PC-RO3 HD096510 and SL RO1 HD072929.

Acknowledgments: We thank Sylvia Gugino, Carmon Koenigsknecht, Justin Helman, and Lori Nielsen for their valuable contributions at the Center for Developmental Biology of the Lung, University at Buffalo.

Conflicts of Interest: The authors declare no conflict of interest.

\section{References}

1. Abman, S.H.; Hansmann, G.; Archer, S.L.; Ivy, D.D.; Adatia, I.; Chung, W.K.; Hanna, B.D.; Rosenzweig, E.B.; Raj, J.U.; Cornfield, D.; et al. Pediatric Pulmonary Hypertension: Guidelines From the American Heart Association and American Thoracic Society. Circulation 2015, 132, 2037-2099. [CrossRef]

2. Evans, N.J.; Archer, L.N. Doppler assessment of pulmonary artery pressure and extrapulmonary shunting in the acute phase of hyaline membrane disease. Arch. Dis. Child. 1991, 66, 6-11. [CrossRef] [PubMed]

3. Halliday, H.; Hirschfeld, S.; Riggs, T.; Liebman, J.; Fanaroff, A.; Bormuth, C. Respiratory distress syndrome: Echocardiographic assessment of cardiovascular function and pulmonary vascular resistance. Pediatrics 1977, 60, 444-449. [PubMed]

4. Skinner, J.R.; Boys, R.J.; Hunter, S.; Hey, E.N. Pulmonary and systemic arterial pressure in hyaline membrane disease. Arch. Dis. Child. 1992, 67, 366-373. [CrossRef] [PubMed]

5. Walther, F.J.; Benders, M.J.; Leighton, J.O. Persistent pulmonary hypertension in premature neonates with severe respiratory distress syndrome. Pediatrics 1992, 90, 899-904.

6. Mourani, P.M.; Abman, S.H. Pulmonary vascular disease in bronchopulmonary dysplasia: Pulmonary hypertension and beyond. Curr. Opin. Pediatr. 2013, 25, 329-337. [CrossRef]

7. Mourani, P.M.; Abman, S.H. Pulmonary Hypertension and Vascular Abnormalities in Bronchopulmonary Dysplasia. Clin. Perinatol. 2015, 42, 839-855. [CrossRef]

8. Mourani, P.M.; Ivy, D.D.; Gao, D.; Abman, S.H. Pulmonary vascular effects of inhaled nitric oxide and oxygen tension in bronchopulmonary dysplasia. Am. J. Respir. Crit. Care Med. 2004, 170, 1006-1013. [CrossRef]

9. Walsh-Sukys, M.C.; Tyson, J.E.; Wright, L.L.; Bauer, C.R.; Korones, S.B.; Stevenson, D.K.; Verter, J.; Stoll, B.J.; Lemons, J.A.; Papile, L.A.; et al. Persistent pulmonary hypertension of the newborn in the era before nitric oxide: Practice variation and outcomes. Pediatrics 2000, 105, 14-20. [CrossRef]

10. Inhaled nitric oxide in term and near-term infants: Neurodevelopmental follow-up of the neonatal inhaled nitric oxide study group (NINOS). J. Pediatr. 2000, 136, 611-617. [CrossRef]

11. Konduri, G.G.; Vohr, B.; Robertson, C.; Sokol, G.M.; Solimano, A.; Singer, J.; Ehrenkranz, R.A.; Singhal, N.; Wright, L.L.; Van Meurs, K.; et al. Early inhaled nitric oxide therapy for term and near-term newborn infants with hypoxic respiratory failure: Neurodevelopmental follow-up. J. Pediatr. 2007, 150, 235-240. [CrossRef] [PubMed]

12. Lakshminrusimha, S.; Swartz, D.D.; Gugino, S.F.; Ma, C.X.; Wynn, K.A.; Ryan, R.M.; Russell, J.A.; Steinhorn, R.H. Oxygen concentration and pulmonary hemodynamics in newborn lambs with pulmonary hypertension. Pediatr. Res. 2009, 66, 539-544. [CrossRef]

13. Rudolph, A.M.; Heyman, M.A. Fetal and neonatal circulation and respiration. Annu. Rev. Physiol. 1974, 36, 187-207. [CrossRef] [PubMed] 
14. Rudolph, A.M.; Heymann, M.A. The fetal circulation. Annu. Rev. Med. 1968, 19, 195-206. [CrossRef] [PubMed]

15. Rudolph, A.M.; Yuan, S. Response of the pulmonary vasculature to hypoxia and H+ ion concentration changes. J. Clin. Investig. 1966, 45, 399-411. [CrossRef]

16. Sorensen, A.; Holm, D.; Pedersen, M.; Tietze, A.; Stausbol-Gron, B.; Duus, L.; Uldbjerg, N. Left-right difference in fetal liver oxygenation during hypoxia estimated by BOLD MRI in a fetal sheep model. Ultrasound Obstet. Gynecol. 2011, 38, 665-672. [CrossRef] [PubMed]

17. Chandrasekharan, P.; Lakshminrusimha, S. Oxygen therapy in preterm infants with pulmonary hypertension. Semin. Fetal Neonatal Med. 2020, 25, 101070. [CrossRef]

18. Villanueva, M.E.; Zaher, F.M.; Svinarich, D.M.; Konduri, G.G. Decreased gene expression of endothelial nitric oxide synthase in newborns with persistent pulmonary hypertension. Pediatr. Res. 1998, 44, 338-343. [CrossRef]

19. Lewis, A.B.; Heymann, M.A.; Rudolph, A.M. Gestational changes in pulmonary vascular responses in fetal lambs in utero. Circ. Res. 1976, 39, 536-541. [CrossRef]

20. Rasanen, J.; Wood, D.C.; Debbs, R.H.; Cohen, J.; Weiner, S.; Huhta, J.C. Reactivity of the human fetal pulmonary circulation to maternal hyperoxygenation increases during the second half of pregnancy: A randomized study. Circulation 1998, 97, 257-262. [CrossRef]

21. Teitel, D.F.; Iwamoto, H.S.; Rudolph, A.M. Changes in the pulmonary circulation during birth-related events. Pediatr. Res. 1990, 27, 372-378. [CrossRef] [PubMed]

22. Lakshminrusimha, S. The pulmonary circulation in neonatal respiratory failure. Clin. Perinatol. 2012, 39, 655-683. [CrossRef] [PubMed]

23. Lumb, A.B.; Slinger, P. Hypoxic pulmonary vasoconstriction: Physiology and anesthetic implications. Anesthesiology 2015, 122, 932-946. [CrossRef] [PubMed]

24. Moudgil, R.; Michelakis, E.D.; Archer, S.L. Hypoxic pulmonary vasoconstriction. J. Appl. Physiol. (1985) 2005, 98, 390-403. [CrossRef]

25. American Academy of Pediatrics and American Heart Association. Textbook of Neonatal Resuscitation $(N R P), 7$ th ed.; American Academy of Pediatrics and American Heart Association: Elk Grove Village, IL, USA, 2016; p. 326.

26. Lakshminrusimha, S.; Manja, V.; Mathew, B.; Suresh, G.K. Oxygen targeting in preterm infants: A physiological interpretation. J. Perinatol. 2015, 35, 8-15. [CrossRef]

27. Castillo, A.; Sola, A.; Baquero, H.; Neira, F.; Alvis, R.; Deulofeut, R.; Critz, A. Pulse oxygen saturation levels and arterial oxygen tension values in newborns receiving oxygen therapy in the neonatal intensive care unit: Is $85 \%$ to $93 \%$ an acceptable range? Pediatrics 2008, 121, 882-889. [CrossRef] [PubMed]

28. Martin, R.J.; Okken, A.; Rubin, D. Arterial oxygen tension during active and quiet sleep in the normal neonate. J. Pediatr. 1979, 94, 271-274. [CrossRef]

29. Bachman, T.E.; Iyer, N.P.; Newth, C.J.L.; Ross, P.A.; Khemani, R.G. Thresholds for oximetry alarms and target range in the NICU: An observational assessment based on likely oxygen tension and maturity. BMC Pediatr. 2020, 20, 317. [CrossRef]

30. Lakshminrusimha, S.; Steinhorn, R.H.; Wedgwood, S.; Savorgnan, F.; Nair, J.; Mathew, B.; Gugino, S.F.; Russell, J.A.; Swartz, D.D. Pulmonary hemodynamics and vascular reactivity in asphyxiated term lambs resuscitated with 21 and 100\% oxygen. J. Appl. Physiol. (1985) 2011, 111, 1441-1447. [CrossRef]

31. Custer, J.R.; Hales, C.A. Influence of alveolar oxygen on pulmonary vasoconstriction in newborn lambs versus sheep. Am. Rev. Respir. Dis. 1985, 132, 326-331. [CrossRef]

32. Lakshminrusimha, S.; Russell, J.A.; Steinhorn, R.H.; Swartz, D.D.; Ryan, R.M.; Gugino, S.F.; Wynn, K.A.; Kumar, V.H.; Mathew, B.; Kirmani, K.; et al. Pulmonary hemodynamics in neonatal lambs resuscitated with $21 \%, 50 \%$, and $100 \%$ oxygen. Pediatr. Res. 2007, 62, 313-318. [CrossRef]

33. Lakshminrusimha, S.; Kinsella, J.P.; Krishnan, U.S.; Van Meurs, K.; Edwards, E.M.; Bhatt, D.R.; Chandrasekharan, P.; Oei, J.L.; Manja, V.; Ramanathan, R.; et al. Just Say No to iNO in Preterms-Really? J. Pediatr. 2020, 218, 243-252. [CrossRef] [PubMed]

34. Kinsella, J.P.; Ivy, D.D.; Abman, S.H. Ontogeny of NO activity and response to inhaled NO in the developing ovine pulmonary circulation. Am. J. Physiol. 1994, 267, H1955-H1961. [CrossRef] [PubMed] 
35. Lesneski, A.; Hardie, M.; Ferrier, W.; Lakshminrusimha, S.; Vali, P. Bidirectional Ductal Shunting and Preductal to Postductal Oxygenation Gradient in Persistent Pulmonary Hypertension of the Newborn. Children 2020, 7, 137. [CrossRef] [PubMed]

36. Rawat, M.; Chandrasekharan, P.; Gugino, S.F.; Koenigsknecht, C.; Nielsen, L.; Wedgwood, S.; Mathew, B.; Nair, J.; Steinhorn, R.; Lakshminrusimha, S. Optimal Oxygen Targets in Term Lambs with Meconium Aspiration Syndrome and Pulmonary Hypertension. Am. J. Respir. Cell Mol. Biol. 2020, 63, 510-518. [CrossRef]

37. Barrington, K.J. Umbilical artery catheters in the newborn: Effects of position of the catheter tip. Cochrane Database Syst. Rev. 2000, CD000505. [CrossRef]

38. Plotz, F.B.; van Lingen, R.A.; Bos, A.P. Venous oxygen measurements in the inferior vena cava in neonates with respiratory failure. Crit. Care 1998, 2, 57-60. [CrossRef]

39. Yapakci, E.; Ecevit, A.; Ince, D.A.; Gokdemir, M.; Tekindal, M.A.; Gulcan, H.; Tarcan, A. Inferior Vena Cava Oxygen Saturation during the First Three Postnatal Days in Preterm Newborns with and without Patent Ductus Arteriosus. Balk. Med. J. 2014, 31, 230-234. [CrossRef]

40. Chandrasekharan, P.; Rawat, M.; Gugino, S.F.; Koenigsknecht, C.; Helman, J.; Nair, J.; Vali, P.; Lakshminrusimha, S. Effect of various inspired oxygen concentrations on pulmonary and systemic hemodynamics and oxygenation during resuscitation in a transitioning preterm model. Pediatr. Res. 2018, 84, 743-750. [CrossRef] [PubMed]

41. Rawat, M.; Chandrasekharan, P.K.; Swartz, D.D.; Mathew, B.; Nair, J.; Gugino, S.F.; Koenigsknecht, C.; Vali, P.; Lakshminrusimha, $\mathrm{S}$. Neonatal resuscitation adhering to oxygen saturation guidelines in asphyxiated lambs with meconium aspiration. Pediatr. Res. 2016, 79, 583-588. [CrossRef] [PubMed]

42. Collins, J.A.; Rudenski, A.; Gibson, J.; Howard, L.; O’Driscoll, R. Relating oxygen partial pressure, saturation and content: The haemoglobin-oxygen dissociation curve. Breathe (Sheff) 2015, 11, 194-201. [CrossRef] [PubMed]

43. Afzal, B.; Chandrasekharan, P.; Tancredi, D.J.; Russell, J.; Steinhorn, R.H.; Lakshminrusimha, S. Monitoring Gas Exchange During Hypothermia for Hypoxic-Ischemic Encephalopathy. Pediatr. Crit. Care Med. 2019, 20, $166-171$. [CrossRef] [PubMed]

(C) 2020 by the authors. Licensee MDPI, Basel, Switzerland. This article is an open access article distributed under the terms and conditions of the Creative Commons Attribution (CC BY) license (http://creativecommons.org/licenses/by/4.0/). 